\title{
DIREITO TERRITORIAL INDÍGENA: ENTRE A OCUPAÇÃO TRADICIONAL E A PRODUÇÃO DO SUSTENTO
}

\author{
Henrique Aniceto Kujawa ${ }^{1}$ \\ Fernando Tonet ${ }^{2}$
}

\begin{abstract}
Resumo
O presente artigo expõe as evoluções das políticas públicas ligadas às demarcações das terras indígenas no estado do Rio Grande do Sul; as atuais formas de utilização das terras indígenas, bem como parcerias entre brancos e índios na aldeia indígena dos Ventarra localizada no município de Erebango, os enfrentamentos e bloqueios públicos através dos órgãos Ministério Público Federal e Polícia Federal. Assim, cria-se o paradoxo questionado no texto: a) Quais são as necessidades dos indígenas na atualidade? b) de que forma o uso da terra pode suprir estas necessidades? c) a possibilidade de uma nova visão nas políticas públicas que aceitem a participação dos brancos, igualando em objetivos sociais as diferentes culturas. $\mathrm{O}$ método utilizado para investigação foi o bibliográfico e empírico, onde foram coletados dados e informações diretamente na aldeia indígena dos Ventarra.
\end{abstract}

Palavras-chave: Aldeia Indígena; Auto desenvolvimento; Etnodesenvolvemento; Multiculturalismo; Políticas Públicas.

\section{INTRODUÇÃO}

O direito territorial indígena tem sido historicamente pauta de discussões jurídicas e de enfrentamentos sociais no tocante à identificação, delimitação e demarcação de áreas indígenas e, mais recentemente, sobre o direito e a forma de uso das Terras Indígenas (TIs) já delimitadas e demarcadas.

A Constituição Federal de 1988, centralmente nos artigos 231 e 232, garante às comunidades indígenas o direito sobre o território que tradicionalmente ocupam, anulando possíveis títulos nelas existentes. Contudo, resta o debate jurídico sobre a existência ou não de marco temporal que interfira no reconhecimento da ocupação tradicional, sobre os critérios utilizados para caracterizá-las, bem como, sobre o papel exercido pelos Laudos Antropológicos e pela Fundação Nacional do Índio (Funai). Para além disso, há um acirramento dos conflitos sociais, principalmente na Região Sul do país, pelo fato dos indígenas reivindicarem terras por eles consideradas de

\footnotetext{
${ }^{1}$ Doutor em Ciências Sociais pela UNISINOS. E-mail: fernando.tonet@hotmail.com

${ }^{2}$ Doutorando em Direito - Unisinos. Email: fernando.tonet@hotmail.com
} 
ocupação tradicional, mas que centenariamente foram destinadas pelo Estado para projetos de colonização e, portanto, desde então estão sendo ocupadas e são propriedades, legalmente constituídas, de agricultores.

No tocante ao direito e a forma de uso das TIs demarcadas, a Constituição estabelece o usufruto (uma vez que a propriedade das mesmas é da União) exclusivo das comunidades indígenas, vetando a participação de terceiros na exploração do solo ou de riquezas naturais. Excetua-se a União, mas mesmo assim precisa do consentimento das Comunidades envolvidas. No entanto, ocorre que, em muitos casos, os indígenas sentem a necessidade de maximizar a produção de riquezas como forma de satisfazer necessidades oriundas de uma aproximação, relação e integração (mesmo que subalterna) com a economia de mercado. Para atingir tal intento, diante das dificuldades culturais (de cultivo extensivo das terras) e econômicas (de viabilizar recursos para a aquisição de maquinários e insumos), recorrem a práticas de arrendamento e/ou parcerias com agricultores e cerealistas, ora questionadas pelo Ministério Público e pela Polícia Federal.

Dentre as tribos indígenas do norte do Rio Grande do Sul, uma em especial vem sofrendo processos judiciais e interferências da Polícia Federal no que tange a participação do homem branco na exploração da terra, os Ventarra, criaram um modelo de parceria entre o povo indígena e os agricultores da região, esse contrato de parceria se resume em: pagamento de porcentagem da safra total pela colheita e transporte dos grãos.

Ocorre que toda intervenção de terceiros é tida como crime por todos os envolvidos, tal fato pode ser verificado nos inúmeros processos em andamento ${ }^{3}$, onde o Ministério Público Federal entende ser crime essas parcerias, ocorre que sem elas a terra indígena fica estéril e improdutiva, pois não tem acesso ao maquinário e implementos para cultivar a terra.

Existem programas no governo brasileiro federal como o Mais Alimentos ${ }^{4}$, onde os agricultores têm acesso à verbas estatais para poder adquirir seus maquinários, infelizmente, como a terra do indígena é da União, os mesmos não têm acesso a esses recursos, fazendo com que, inevitavelmente, as parcerias continuem.

Objetivamos com este artigo refletir sobre o direito e a forma de uso das TIs por parte das Comunidades relacionando as normas vigentes com as políticas públicas estabelecidas e com as condições concretas de

\footnotetext{
3 A Tribo Indígena dos Ventarra vem sofrendo diversos processos nos últimos anos, sobre os processos ver: 500336475.2013.4.04.7117; 5003895-64.2013.4.04.7117; 5001853-08.2014.4.04.7117/TRF; IPL: 0359/2013-DPF/PFO/RS.

${ }^{4} \mathrm{O}$ Mais Alimentos Produção Primária é uma linha de crédito do Pronaf que financia investimentos em infraestrutura produtiva da propriedade familiar. Contempla os seguintes produtos e atividades: açafrão, arroz, cana-de-açúcar, café, centeio, feijão, mandioca, milho, palmácea para produção de palmito, soja, sorgo, trigo, erva-mate, apicultura, aquicultura, avicultura, bovinocultura de corte, bovinocultura de leite, caprinocultura, fruticultura, olericultura, ovinocultura, pesca e suinocultura. Por meio desta linha de crédito são financiados projetos individuais de até R $\$ 150$ mil e coletivos de até R \$ 750 mil, com juros de 2\% ao ano, até três anos de carência e até dez anos para pagar. Para financiamento de estruturas de armazenagem o prazo pode chegar a 15 (quinze) anos, com carência de três anos. Cabe destacar que os financiamentos destinados às atividades de suinocultura, avicultura e fruticultura podem chegar a R\$ 300 mil. Os contratos do Pronaf Mais Alimentos Produção Primária são vinculados ao Programa de Garantia de Preços da Agricultura Familiar (PGPAF). Informações contidas no site do governo: http://portal.mda.gov.br/portal/saf/maisalimentos/ (acesso em 07 de abril de 2015).
} 
comunidades indígenas kaingang do Rio Grande do Sul. Teoricamente, nos utilizaremos dos conceitos de etnodesenvolvemento (STAVENHAGEN, 1984; VERDUM, 2006), fricção interétnica (OLIVERIA, 1978, 2000) e diversidade emergente (NAVARRETE, 2008) para compreendermos a realidade indígena em análise, bem como, suas necessidades e novas formas de uso da terra. Metodologicamente, para além da revisão bibliográfica, nos utilizaremos do estudo de um caso concreto da comunidade de Ventarra (Erebango e Erechim) onde, motivado pela atuação do Ministério Público Federal, houve o questionamento da forma de uso da terra e as decorrentes parcerias da Comunidade com agricultores e cerealistas.

Estruturamos o texto, para além da introdução e considerações finais, em três tópicos. No primeiro buscaremos resgatar a trajetória da política pública que definiu as terras indígenas no Rio Grande do Sul e as repercussões geradas nas formas de uso das mesmas. No segundo faremos uma caracterização da comunidade que ocupa a TI de Ventarra analisando sua forma de uso da terra, a forma de auto sustento e as implicações da recente atuação do MPF no intuito de coibir a participação de terceiros no cultivo agrícola. No terceiro faremos uma análise, tendo presente trajetória histórica da política territorial indígena e do caso concreto de Ventarra, das diferentes compreensões da diversidade indígena (Primordial e emergente) e as implicações nas formas de uso das terras.

\section{TRAJETÓRIA DA DEFINIÇÃO E USO DAS TERRAS INDÍGENAS NO RIO GRANDE DO SUL}

A política territorial indigenista no Período Imperial brasileiro é marcada por dois momentos distintos. $\mathrm{O}$ primeiro deles inaugurado com o Ato Adicional de 1834, que se constituiu em uma reformulação da constituição de 1824, pelo qual transfere para as províncias brasileiras a tarefa de legislar sobre o direito indígena e promover políticas de catequização, civilização e integração dos mesmos à sociedade nacional. Esta descentralização está fortemente ligada ao debate, próprio do período regencial, que girava em torno da excessiva centralização do poder imperial e da necessidade de ampliar a autonomia das províncias e das elites regionais. Esta normatização inaugurou um período de fragmentação das políticas indigenistas vinculadas às diferentes concepções dos governos e aos interesses econômicos, políticos e sociais de cada província.

O advento do Segundo Reinado, o processo de pacificação e/ou alinhamento das províncias fez com que D. Pedro II voltasse a chamar para si a tarefa de legislar e instituir uma política para os "índios não integrados". O Decreto Imperial número 426, de 24 de julho de 1845, criou o Regulamento das Missões. Segundo Pezat (1997, p. 257), "através deste decreto, o poder central retomou a prerrogativa de determinar as diretrizes da política indigenista, que antes estava a cargo dos poderes locais". Das diretrizes estabelecidas por este decreto merecem destaque as seguintes: a primeira delas é de que os indígenas que viviam como nômades deveriam ser 
estabelecidos em aldeias destinadas ao seu agrupamento para que pudessem desfrutar de um espaço específico para o seu desenvolvimento; a segunda que no intuito de criar uma política centralizada, mas ao mesmo tempo capilarizada capaz de atingir as diferentes regiões do Brasil, estabeleceu que em cada uma das províncias fosse criada uma "Diretoria Geral dos Índios" sob a responsabilidade de um diretor que seria nomeado pelo imperador e que cabia aos presidentes das províncias nomear um diretor leigo para cada aldeia, bem como atrair missionários com a tarefa de realizar a catequização e a assistência religiosa dos indígenas nestas aldeias, abordando o papel do diretor leigo de cada aldeia Pezat (2007, p. 257) menciona que cada um deles "[...] teria por responsabilidade zelar para que os indígenas não fossem vítimas de violência por parte de nacionais, contendo-os nos limites do estabelecimento oficial e procurando sedentarizá-los através do ensino de técnicas agrícolas". Reforçamos que, em que pese a orientação teórica, absolutamente hegemônica na época, de integração dos indígenas na sociedade brasileira, havia claramente uma preocupação com a definição das terras indígenas como condição de sua preservação.

O Rio Grande do Sul procurou, através do seu presidente Luiz Alves de Lima e Silva (Duque de Caxias), implementar o decreto Imperial e regulamentar a constituição e funcionamento de aldeias indígenas, principalmente no Norte do estado onde viviam os índios Kaingang e também havia a necessidade de garantir maior segurança dos limites fronteiriços constantemente ameaçados pelos países vizinhos. Nesse período, foram criadas as aldeias de Nonoai e de Guarita e inicialmente (1846), até o imperador não nomear o Diretor Geral dos Índios para o Rio Grande do Sul, Conde de Caxias estabeleceu que João Cypriano Rocha Lourdes (tenente da Guarda Nacional e coletor de impostos) ocuparia o cargo, sendo no ano seguinte (1847) substituído por José Joaquim de Andrade Neves indicado por D. Pedro II. Também em 1847 iniciam-se as tratativas pelo então presidente provincial, Manoel Antônio Galvão, para a vinda dos Jesuítas espanhóis para contribuir no processo de aldeamento e catequização dos indígenas que resultou na vinda dos padres Bernardo Parés, Santiago Villarubia e Julián Solanelas 5 .

No mesmo período, se ampliou a atuação da Província, através dos missionários Jesuítas e depois Franciscanos, para o processo de aldeamento dos indígenas da região de Passo Fundo (Mato Castelhano e Campo do Meio) Lagoa Vermelha, Vacaria e Encosta da Serra, contudo, pela importância deste tema para o presente estudo, abordaremos no próximo item ao tratarmos do processo de ocupação de Passo Fundo e Mato Castelhano (BECKER 1995). Com a instauração do Estado Republicano e intensificação da imigração no Sul do país e com o fortalecimento das ideias positivistas cresce também o debate sobre a relação com os indígenas, principalmente quanto ao papel do Estado na condução de uma política laica e na demarcação de territórios

\footnotetext{
${ }^{5}$ Um estudo aprofundado sobre a constituição do Aldeamento de Nonoai e da atuação dos jesuítas neste período ver Rückert; $\operatorname{Kujawa}(2010)$.
} 
específicos para estes grupos étnicos. A tese que prosperava entre os positivistas, é a de que o Estado deveria, através de uma política laica, desenvolver uma estrutura de proteção e integração dos povos indígenas. Fruto deste pensamento positivista, com atuação destacada do Marechal Rondon, surge o Serviço de Proteção aos Índios e Localização dos Trabalhadores Nacionais (SPLITN), em 1910, buscando afastar a atuação missionária e clerical e desenvolver uma estrutura do Estado que atendesse à necessidade de proteção e integração dos indígenas. (GAGLIARD, 1989)

É dentro deste contexto que o estado do Rio Grande do Sul, a partir do governo do Partido Republicano Rio-Grandense (PRR), fortemente influenciado pelos princípios positivistas, intensifica uma política de demarcação das aldeias indígenas. É importante destacar que, pela Constituição Federal de 1891 (artigo 64), a tarefa de identificar as terras devolutas e promover a sua colonização passa a ser dos estados. No caso do Rio Grande do Sul, soma-se a este contexto a pressão por ocupação de novas áreas, consideradas devolutas por imigrantes e seus descendentes que se deslocam das primeiras áreas colonizadas rumo ao nordeste e norte do estado, em busca de terras para o cultivo e a garantia de sobrevivência de suas famílias.

$\mathrm{Na}$ expectativa de proteção aos índios e constituição de novas áreas para loteamento colonial e venda para os descendentes de imigrantes, o Estado do Rio Grande do Sul demarca e delimita, entre 1910 e 1918, onze áreas indígenas, em terras consideradas devolutas, portanto, de sua propriedade. Simultaneamente divide as terras devolutas em milhares de lotes que são vendidos para colonos descendentes de imigrantes ou então caboclos/nacionais que já viviam na região como intrusos ${ }^{6}$. Percebe-se que o Estado, ao fazer estas demarcações e loteamento, define o território a ser destinado para os indígenas e o território para os colonos. A existência dos toldos a serem demarcados são mencionados no Relatório da Secretaria das Obras Públicas ao Presidente do Estado do Rio Grande do Sul de 1910. Torres Gonçalves enumera doze toldos, quatro localizados no então município de Palmeira das Missões (toldos de Inhacorá, de Nonoai, da Serrinha, e de Guarita) cinco em Passo Fundo (Ligeiro, Carreteiro, Ventarra, Erechim e Votouro) dois em Lagoa Vermelha (Fachinal e Caseros) e um em Soledade (Lagoão). Nos relatórios dos anos seguintes é noticiada a demarcação dos referidos Toldos em 1911, os Todos de Ligeiro, Fachinal (Cacique Doble), Caseros, Carreteiro e Ventara e Erechim reunidos num único toldo com 753 hectares. No relatório de 1912 é referida a demarcação dos Toldos de Nonoai e de Serrinha. No relatório de 1918 é noticiada a demarcação de Inhacorá, Guarita e Votouro.

\footnotetext{
${ }^{6} \mathrm{O}$ tratamento dispensado aos caboclos, chamados normalmente de nacionais, pela diretoria de terras não é objeto deste estudo, mas cabe apenas destacar que estes faziam parte da preocupação central de Torres Gonçálves, que em acordo com os princípios da Igreja Positivista do Brasil condenava o processo de indução de imigração européia e defendia uma política de incorporação dos nacionais no processo de colonização inclusive estipulando uma política facilitada para que obtivessem a legalização dos seus lotes e a criação de colonizações mistas (PEZAT 1997; RÜCKERT, KUJAWA 2010).
} 


\section{A redução das Terras Indígenas historicamente demarcadas}

O processo de demarcação das terras indígenas não significou o fim da pressão territorial provocada pela expansão agrícola, pela exploração da madeira e pela expansão demográfica. A própria política indigenista desenvolvida pelo SPI buscava estabelecer a sustentabilidade das reservas indígenas através da produção de alimentos a partir do trabalho dos índios ou através da exploração direta e indireta das riquezas nelas existentes. $\mathrm{O}$ relatório da CPI do Índio da Assembléia Legislativa do Rio Grande do Sul deixa muito claro que haviam contratos firmados entre o Serviço de Proteção ao Índio e particulares para extração de madeira ${ }^{7}$. Mas, a questão central é que o processo de exploração da madeira não se dava apenas a partir dos contratos formais. Estes contratos acabavam sendo apenas uma porta de entrada para a derrubada e roubo generalizado como se pode verificar em denúncias feitas pela imprensa na década de 1960 .

Tendo em vista os roubos de madeira que se sucedem no Toldo de Nonoai, área do Estado sob administração do Serviço de Proteção ao Índio, o sr. Fernando Gonçalves, diretor geral do IGRA, telegrafou ontem, ao ser Anísio de Carvalho, chefe daquele órgão, solicitando providências urgentes para eliminação das irregularidades. (...) Informo ainda que recebi comunicação de incêndio possivelmente criminoso que danificou aproximadamente 1.200 pinheiros" (O Dia, Porto Alegre, 11/08/1965, p.2 apud Relatório da CPI fols13)

A notícia, embora seja específica da área de Nonoai, denuncia uma prática que parece ter sido generalizada de exploração da madeira, utilizando-se de contratos formais ou até de artimanhas de incêndios para justificar que aquelas árvores estavam mortas e, portanto, poderiam ser retiradas (RELATÓRIO DA CPI, fl. 16).

Uma segunda questão a ser ressaltada é que o processo de exploração das terras indígenas por terceiros acontecia pela prática do intrusamento e pela prática do arrendamento. Entendemos como intrusamento os processos não formais de ocupação de terras indígenas por posseiros que faziam o "arrachamento" e o cultivo de pequenas lavouras. Por serem informais não significa que não tinham o consentimento dos administradores do Estado e de lideranças indígenas, numa rede que envolvia vantagens financeiras, processo de corrupção, relações de poder e violência ${ }^{8}$.

A prática do arrendamento era fruto de contratos estabelecidos entre o SPI, através do administrador do Posto Indígena com agricultores ou pequenos fazendeiros onde se estabelecia o pagamento de $20 \%$ da produção para o Posto Indígena. Esta prática era amplamente adotada como pode-se perceber pelo informe que o representante do IGRA (Instituto Gaúcho de Reforma Agrária) à CPI do Índio, através do depoimento de Israel

\footnotetext{
${ }^{7}$ No caso específico da TI de Nonoai, durante muitos anos, este contratos foram com a empresa Hermínio Tissiani e Sartorretoe Cia. Ltda e, na década de 1960, houve uma nova licitação onde a empresa Julio Gasparotto comprou o direito de retirar três mil pinheiros

${ }^{8}$ Carini (2005) ao tratar deste tema, tendo como objeto de estudo a Terra Indígena de Serrinha explicita "Os acertos com os guardas florestais, responsáveis pelo posto de fiscalização, ou com os próprios diretores de terras públicas, visando à abertura de roças, a retirada de madeira e arranchamento definitivo, eram frequentes e envolviam o pagamento de propinas, promessas, parcerias e arrendamentos" ( p.152)
} 
Farrapo Machado mencionando "que ao ficar sabendo oficialmente do problema de intrusão em Nonoai, em 1963, solicita um relatório ao chefe da secção de Faixa de Fronteira, Sr. João Muniz Reis, feito em julho de 1963, onde se constata cinquenta e três arrendatários que mantinham contratos com o Posto Indígena, e quinze intrusos chamados 'sem terra' " (RIO GRANDE DO SUL, 1968 fl.33)9.

Assim, fica evidente que a terra indígena, mesmo demarcada, não estava a serviço exclusivo do seu desenvolvimento. Compreendemos que isso ocorria por dois fatores centrais: a) a concepção da política indigenista estava permeada pelas ideias de integração do indígena transformando-o num agricultor e de auto sustento econômico das terras; b) na prática a exploração das riquezas das terras demarcadas, administradas por instituições públicas era conduzida de forma a privilegiar, através de atos lícitos e ilícitos, particulares e os próprios administradores dos Toldos ${ }^{10}$.

A questão territorial indígena tornou-se mais complexa na medida em que o estado do Rio Grande do Sul, entre as décadas de 1940 e 1960 desenvolve uma política de redução das áreas indígenas historicamente demarcadas destinando-as para a constituição de áreas florestais e para o assentamento de agricultores sem-terra. Este processo culmina com a extinção de áreas indígenas (Serrinha, Ventarra e Monte Caseiros) e redução das demais com exceção de Carreteiro. As motivações que levaram ao ente público a efetivar tal política já foi amplamente discutida pela bibliografia especializada (CARINNI, 2005; SIMONIAN, 2009; KUJAWA,2014b), o que importa para o objetivo deste artigo é frisar que, na prática, os indígenas que viviam no Rio Grande do Sul, não transformaram-se efetivamente em agricultores e tiveram suas terras reduzidas sem nenhum tipo de compensação.

\section{A reconstituição das Terras Indígenas e os novos desafios}

Após a constituição de 1988 - a consolidação do direito territorial indígena, do reconhecimento da cultura indígena, do fim da condição de tutelado e dos princípios que orientavam a ação do Estado no intuito de integração indígena - a atuação do movimento indígena e das entidades indigenistas (centralmente o Conselho Indigenista Missionário - CIMI) levaram o Estado do Rio grande do Sul a reconhecer que havia cometido irregularidades com os atos de redução das TIs historicamente demarcadas.

\footnotetext{
${ }^{9} \mathrm{O}$ pagamento de arrendamento é relatado no depoimento da absoluta maioria dos agricultores que prestaram informações à CPI e atestada também por outros depoentes como é o caso do o Vereador Aloides Rech que em depoimento a CPI relata "(..) que a maioria dos atuais ocupantes paga arrendamento ao Pôsto, com ou sem contrato. Que esse pagamento é feito na forma percentual de colheita a razão de 20\% (...)" (Relatório da CPI fl. 127). O depoimento de Nilson de Assis Castro, chefe do Posto Indígena relata a contabilidade do arrendamento da safra 1965/66 "uma soma de 16.885 kilos de feijão, 59.524 kilos de milho, 4.811 kilos de arroz e 10.075 kilos de trigo" (RIO GRANDE DO SUL, 1968 Fls 109. Além disso, o próprio IGRA cadastrava os agricultores presentes nas áreas indígenas, lhe fornecia um cadastro e cobrava os tributos equivalentes, fato este que comprova o pleno conhecimento das práticas de arrendamento e intrusão pelas diferentes instâncias e instituições públicas nas esferas estadual e federal.
} 
Isso ocorreu por parte do Legislativo quando cunhou no Art. 32 da constituição estadual a responsabilidade do estado restituir os limites das referidas áreas e reassentar e/ou indenizar os agricultores. Da mesma forma o executivo constitui um Grupo de Trabalho para fazer um estudo de quais áreas tinham sido reduzidas (RIO GRANDE DO SUL, 1997) e inicia ações com o intuito de restituição dos limites originais das TIs historicamente demarcadas. Obviamente este processo foi extremamente penoso, para os indígenas que necessitaram organizar-se (acampamentos, ocupações, trancamento de rodovias) para pressionarem os governos a agilizarem as restituições. Para os agricultores que haviam comprado as terras do Estado (décadas de 1950/60) agora precisavam abandoná-las, mesmo com escrituras registradas. O impacto gerado para este grupo social não se restringia ao valor da indenização e/ ou locar para o reassentamento, pois estava desconstituindo laços culturais, religiosos e comunitários construídos por quatro décadas (CARINI, 2005).

A demarcação das Toldos Indígenas (1910-18) não cessou os conflitos territoriais entre indígenas e não indígenas provocados pelo modelo de uso da terra, pela forma como o estado conduzia a administração das mesmas e pelo desejo de particulares explorarem-nas resultando na diminuição das áreas indígenas descritas acima. Da mesma forma a restituição dos limites das referidas áreas trouxeram questões de duas ordens que tem acirrado os conflitos territoriais. Uma das questões é movimento político indígena denominado de "retomada" (VEIGA, 2010) que passou a reivindicar a demarcação de novas TIs, consideradas por eles de ocupação tradicional, em locais centenariamente colonizados pelo estado que loteou e vendeu para agricultores no início do século XX. Na região norte do Rio Grande do Sul tem mais de 15 acampamentos indígenas, alguns com mais de 10 anos, na beira das rodovias em terras públicas e privadas, reivindicando novas demarcações. Este processo vem acirrando os conflitos tendo de um lado os indígenas com a expectativa de ampliação do seu território e de outro os agricultores que sentem a ameaça da perda das propriedades e rompimento de ações culturais e territoriais construídas centenariamente.

A segunda questão é a forma de utilização das terras indígenas demarcadas e em que medida elas atendem o disposto na Constituição, principalmente no seu Art.31, inciso XX, que determina o uso exclusivo destas terras por indígenas. Mesmo que estas duas questões possam ter estreitas relações, uma vez que a necessidade de ampliação territorial indígena possa estar motivada pela forma de utilização das atuais TIs (VEIGA, 2010, KUJAWA,2014b, MINISTÉRIO PÚBLICO FEDERAL), nos cabe, no âmbito deste texto, levantarmos algumas reflexões específicas sobre a segunda questão.

1. O direito territorial indígena está vinculado à ocupação tradicional e a utilização para a manutenção e desenvolvimento de suas características sociais, culturais e econômicas. Simultaneamente as relações estabelecidas com a sociedade envolvente (ficção interétnica) e a constituição histórica de sua

\footnotetext{
${ }^{10}$ Toldo era o nome dado às áreas demarcadas oficialmente como indígenas.
} 
diversidade (diversidade emergente) alteraram significativamente as formas tradicionais de vida indígena e produziram novas relações e necessidades que os integraram, mesmo que subalternamente, ao mercado. Diante desta perspectiva qual é função e quais são as formas de organização das terras indígenas.

2. Tendo presente a autonomia cultural indígena e o direito ao etnodesenvolvimento, como as políticas públicas indigenistas não incorram, de forma invertida, no mesmo problema do século XX. No passado buscava integrar o indígena transformando-os em agricultores nacionais e/ou agricultores e agora imaginando que os indígenas vão reestabelecer formas de vida tradicionais, extrativistas, de subsistência, desvinculados da sociedade produtiva e de consumo.

Antes de aprofundarmos estas reflexões vamos descrever a realidade da TI de Ventarra, municípios de Erebango e Erechim no Rio Grande do Sul, que foi uma das áreas extinta na década de 1960, restituída na década de 1990 e recentemente está sendo pauta de intervenção do Ministério Público Federal e da Polícia Federal questionando a forma de utilização e exploração das terras.

\section{DAS CARACTERÍSTICAS DA TRIBO INDÍGENA DE VENTARRA}

A reserva indígena dos Ventarra foi originalmente demarcada no ano de 1911, pelo governo estadual do Rio Grande do Sul, por volta dos anos 1960 a 1965, todos os indígenas que habitavam na região foram expulsos por funcionários do governo, ligados a inspetoria de terras de Erechim. A (re)demarcação ocorreu no ano de 1993, e o processo de ocupação foi concluído no ano de 1998. No ano de 2005 existiam 270 indígenas residindo na TI de Ventarra ${ }^{11}$.

No ano de 2015, a TI dos Ventarra, possui uma população indígena de 350 pessoas, divididas em 80 famílias, todos envolvidos com a agricultura familiar e empregos ligados a SESAI (Secretaria Especial de Saúde Indígena).

Com o modelo de parceria com os agricultores da região, os indígenas do Ventarra evitaram o arrendamento de terras, e puderam investir em sua comunidade, fortalecendo os laços culturais e multiculturais entre os indígenas e brancos. Em relatórios a SESAI ${ }^{12}$ informa que não existem na aldeia dos Ventarra casos de óbitos infantis, bem como casos de desnutrição. O mesmo órgão público, tem preocupações com o fim da parceria entre os indígenas e os brancos, pois acredita que essa realidade saudável logo acabará fazendo que as famílias voltem a ter uma escassa condição financeira e acabem voltando às rodoviárias e ruas com suas crianças mendigando por esmolas.

\footnotetext{
${ }^{11}$ Ver: http://www.portalkaingang.org/index_ventarra.htm.
} 
A aldeia dos Ventarra tem uma das maiores produções de grãos dentre as terras indígenas, bem como sua comunidade não passa nenhuma necessidade ${ }^{13}$. Suas habitações, estruturas da saúde, educação e desporto são respaldadas pela SESAI, ocorre que tal parceria está no fim, pois o Ministério Público Federal de Erechim, juntamente com a Polícia Federal de Passo Fundo, acreditam que existe uma ilegalidade na parceria com os agricultores, acarretando um uso ilícito das terras públicas.

\section{Das parcerias entre brancos e indígenas no Ventarra}

Os indígenas do Ventarra têm como sua única forma de sustento os benefícios concedidos pelo plantio de grãos, em geral da plantação de soja em suas terras. Atualmente, a tribo possui 772,95 hectares, dos quais são divididos pelas 80 famílias residentes e pela associação indígena dos Ventarra. Todos os grãos servem como garantia de pagamento aos fornecedores de produtos básicos, ou seja, para o sustento, educação, saúde e o próprio plantio na área.

Os indígenas fazem contas no comércio regional de Erebango e Getúlio Vargas, cujo pagamento é garantido pelas colheitas realizadas entre os meses de março e abril de todos os anos, assim, os comerciantes recebem em grãos anualmente os dividendos feitos pelos indígenas, esses grãos são divididos conforme a faixa de terra estabelecida para cada família indígena. Tal forma de parceria, parcelamento e pagamento é questionada pelos órgãos públicos Ministério Público Federal e Polícia Federal, pois acreditam que os comerciantes recebendo em soja acabam tendo alguma forma de gerenciamento sobre a colheita, o que tem acarretado diversas demandas judiciais. Pois, no entendimento dos órgãos supracitados, a forma de cultivo das terras estaria violando a normativa jurídica ${ }^{14}$ que estabelece o uso exclusivo das Terras Indígenas pelas suas comunidades.

Atualmente, todos os envolvidos com venda de bens e produtos para os indígenas do Ventarra, encontram-se sendo investigados pela Polícia Federal de Passo Fundo e Ministério Público Federal de Erechim,

\footnotetext{
${ }^{12}$ Ofício n. ${ }^{\circ}$ 364/2014 - da Secretaria Especial da Saúde Indígena.

${ }^{13}$ Ofício n. $364 / 2014$ - da Secretaria Especial da Saúde Indígena.

${ }^{14}$ Constituição Federal, art. 231. São reconhecidos aos índios sua organização social, costumes, línguas, crenças e tradições, e os direitos originários sobre as terras que tradicionalmente ocupam, competindo à União demarcá-las, proteger e fazer respeitar todos os seus bens.

$\$ 2 .^{\circ}$ As terras tradicionalmente ocupadas pelos índios destinam-se a sua posse permanente, cabendo-lhes o usufruto exclusivo das riquezas do solo, dos rios e dos lagos nelas existentes.

\$ 3. $\mathrm{O}$ aproveitamento dos recursos hídricos, incluídos os potenciais energéticos, a pesquisa e a lavra das riquezas minerais em terras indígenas só podem ser efetivados com autorização do Congresso Nacional, ouvidas as comunidades afetadas, ficando-lhes assegurada participação nos resultados da lavra, na forma da lei.

$\$ 4 .^{\circ}$ As terras de que trata este artigo são inalienáveis e indisponíveis, e os direitos sobre elas, imprescritíveis.
} 
sob suspeita de usurpação de terras públicas, pois a intervenção de terceiros em terras indígenas seja para a finalidade que for sendo remunerada teoricamente caracterizaria um crime ${ }^{15}$.

Nesse sentido o Ministério Público Federal solicitou o bloqueio da colheita de soja 2013/2014, tal solicitação não foi aceita pelo Tribunal Regional Federal da $4^{\circ}$ Região, pois causaria gravíssimos prejuízos aos indígenas residentes no Ventarra, pois as parcerias seriam fragilizada pela falta de pagamento.

Estabelece-se claramente um paradoxo, pois, nas condições atuais vivida pela comunidade de Ventarra, a suspensão da parceria significa o não plantio das lavouras e com isso o rompimento das condições objetivas que transformaram a aldeia, conforme demonstrado pela própria SESAI, numa das mais bem estruturada, no norte do estado do Rio Grande do Sul, do ponto de vista dos indicadores sociais, condições de moradia e equipamentos comunitários. Por outro lado a alegação dos órgãos que propõem o fim do modelo de gestão da produção da aldeia alegam que o fazem para garantir melhores condições de desenvolvimento para os indígenas.

O referido paradoxo, na prática, expressa o conflito sobre concepções do que seja desenvolvimento indígena e do papel a ser cumprido pelo estado como agente protetor destas comunidades, tema que aprofundaremos no próximo item.

\section{A CONCEPÇÃO DE DIVERSIDADE INDÍGENA E O DIREITO AO USO DA TERRA}

A constituição de 1988 garante o respeito a cultura costumes, tradições indígenas e, simultaneamente a demarcação e o uso exclusivo das terras que tradicionalmente ocupam. Ocorre que permanece o debate sobre quem são os indígenas do século XXI quais são suas necessidades, de que forma que usam a terra para supri-las? Não se trata de negar a diversidade indígena, mas de como esta diversidade é entendida e tratada historicamente pelas sociedades, como se compreendem, se constituem, se reconhecem e se materializam, através de instrumentos jurídicos e de políticas públicas, os seus diretos.

Partindo da análise de Federico Navarrete (2008), caracterizaremos duas perspectivas de análise distintas que se condensam nos conceitos de diversidade primordial e diversidade emergente. A perspectiva da diversidade primordial, parte da compreensão de que a constituição populacional das nações da América teve origem nas diversas ondas migratórias iniciadas com a vinda das populações ameríndias, continuadas com a chegada dos europeus no século XV e, posteriormente com a vinda dos africanos e asiáticos. Neste sentido, a pluralidade é fruto da forma como foi constituída e "tem sido concebida com uma espécie de 'pecado original' das sociedades Américas". (NAVARRETE, 2008, p.90)

\footnotetext{
${ }^{15}$ Relatar que em momento algum o MPF fala em arrendamento de terra indígena, prática comum em outras comunidades, apenas incrimina os brancos que estão recebendo anualmente em produto (uma porcentagem de soja) pelos trabalhos prestados.
} 
Dentro desta perspectiva de análise o processo de colonização europeia, a partir do final do século XV no qual os brancos estavam imbuídos de uma visão de superioridade ocidental - baseada na implantação dos interesses econômicos capitalistas (inicialmente comercial e posteriormente industrial) impedira o reconhecimento desta diversidade, produzindo uma homogeneização excluindo e/ou integrando subalternamente os diferentes grupos dentro do mesmo "processo civilizador" liderado pelo "branco ocidental".

Seguindo esta linha de raciocínio a diversidade étnica existente estaria ligada às raízes originárias dos grupos que constituíram a formação populacional e social e que, no decorrer do período colonial e constituição dos estados nacionais, se mantém a partir de diferentes formas de herança e manutenção das características de seus antepassados e de resistência ao modelo socioeconômico que buscou homogeneizá-los. A diversidade é entendida como "(...) unicamente uma condição originária, o ponto de partida, o cenário prévio e imóvel em que se dão os processos de colonização e de construção nacional". Nesta mesma perspectiva, continua o autor

(...) as diversidades existentes hoje são produtos e a continuação desta diversidade primordial, ou seja, que aquilo que torna diferentes os ameríndios, os afro-americanos (...) é o que eles conservam de suas origens particulares, enquanto sua experiência colonial e nacional não teria demonstrado mais que a tendência de homogeneizá-los (NAVARRETE, 2008, p. 91)

Contrapondo-se ao descrito acima, a perspectiva da diversidade emergente, embora não negue a importância do processo de colonização e de diversos processos migratórios voluntários ou forçados, nem tão pouco nega a existências de continuidades identitárias e culturais, indica que a diversidade deve ser entendida como uma permanente construção que se altera e se constitui historicamente num processo simultâneo de resistência e de integração, de manutenção de heranças e constituição de novas características e necessidades de acordo com o momento histórico. Portanto, a existência do atual quadro de diversidades, escreve Navarrete:

(...) não devem ser concebidas como uma simples continuação, ou um remanescente, das diferenças primordiais, e sim como fenômenos novos, que podem retomar elementos das diferenças previamente existentes, mas que lhes dão sentido e funções diferentes e novas. (2008, p.91)

Durante todo período colonial, mas principalmente no processo de constituição dos estados nacionais houve distintas formas de segregação e de discriminação produzindo, constantemente, diversidades que, mesmo que remetem alguns elementos ao processo de colonização, constituem novos parâmetros para caracterização de grupos étnicos, de seus interesses e de traçados de identidade, bem como da forma com que buscam constituir direitos e forma de relação com o estado e com o conjunto da sociedade.

$\mathrm{Na}$ compreensão de diversidade emergente tem grande importância o conceito de etnogenese compreendendo que os diferentes grupos étnicos mantiveram postura permanente de resistência, mas, simultaneamente de assimilação. Ou seja, estes grupos não foram passivos diante da construção dos estados 
nacionais, mas a partir de seus elementos culturais estabelecem estratégia de resistência e de negociação. Eles aparecem, segundo Navarrete,

(...) nas descrições anteriores como objetos passivos dos processos de construção nacional e expansão do capitalismo, o conceito de etnogenese permite descobrir e compreender as complexas estratégias que desenvolveram para reagir, resistir e negociar com esses processos - e também para, na medida do possível, participar e se beneficiar deles. (2008, p. 95)

A caracterização da diversidade primordial e diversidade emergente pode nos ajudar no entendimento do paradoxo criado na forma de gestão das terras da comunidade indígena de Ventarra. A alegação de que a parceria na gestão viola a norma jurídica que estabelece o uso exclusivo das terras indígenas por suas comunidades, parte do pressuposto que os próprios indígenas não tem capacidade (etnogenese) para gerir suas terras, mesmo que em formato de parceria ou, então, que em terras indígenas não devem ser cultivadas com objetivo comerciais. Reforça-se o estereótipo (algumas vezes romântico, outras interesseiro) do indígena integrado a natureza, independente do padrão de consumo capitalista, exemplos de um comportamento ideal para um novo modelo de sociedade.

Contudo, a partir da perspectiva da diversidade emergente, percebe-se quea realidade destes povos é mais complexa e mais vinculada a sociedade globalizada do século XXI. Bittencourt (2007, p.46) afirma que “(...) não há uma vinculação automática entre o desejo de manter uma cultura distinta e o de isolar-se culturalmente, uma suposição frequentemente elaborada pela sociedade, que tende a exigir "pureza das culturas minoritárias." O processo de contato das comunidades indígenas com as realidades urbanas, as mudanças no seu habitat dos séculos anteriores, resultaram em fricções interétnicas que alteraram significativamente a sua forma de sobrevivências e os elementos que constituem-se em suas necessidades. No caso específico da comunidade de Ventarra, as terras retomadas na década de 1990 estavam sendo intensamente cultivadas pelos agricultores, não se encontram as condições naturais, nem tampouco os indígenas Kaingang, após séculos de fricção interétnica, almejam viver da caça da pesca e da coleta.

A realidade indígena demonstra que grande parte das comunidades indígenas, em que pese a sua cultura tradicional no processo de constituição e reconstituição de sua diversidade, estabeleceram relação como o mercado tornando-os desejosos e dependentes do consumo e, portanto necessitados de fonte de renda. Por isso dentro de uma perspectiva de etnogenes e de diversidade emergente, buscam estabelecer estratégias para se relacionar com outros setores da sociedade e satisfazer as necessidades que se constituem no momento histórico presente. 


\section{CONSIDERAÇÕES FINAIS}

Não se trata de pactuar com processos de exploração de terras indígenas por membros externos, mas sim de entender que elas precisam dar conta das atuais necessidades destas comunidades e que seus líderes, dentro de uma perspectiva de etnogenese, precisam estar presentes na estruturação de estratégias que viabilizem o seu etnodesenvolvimento.

As comunidades indígenas brasileiras vivenciaram, em grau e intensidade diversa, fricções interétnicas, não deixaram de ser indígenas, mas também não são os mesmos de séculos passados. Elementos culturais, formas de relação com a natureza, formas de sustento foram se constituindo e reconstituindo historicamente. É cristalino dentro do sistema jurídico e social, que os indígenas, da comunidade de Ventarra, quando retomaram as terras na década de 1990 não as receberam nas condições naturais de séculos passados, nem estruturadas para poderem usufruir as condições agrícolas das mesmas. As políticas públicas do Brasil que atendem os agricultores familiares, financiam maquinário e implementos usando a terra como garantia, não são acessíveis para os indígenas uma vez que suas terras não podem servir como garantia. Os indígenas não têm acesso a crédito e muito menos aos programas de estímulo a produção como o programa Mais Alimentos do governo federal. Ao mesmo tempo que o Estado não permite o acesso as políticas de estimulo a produção, impede alternativas de viabilização de alternativas produtivas. Parece evidente que a atual política ao invés de proteger o indígena acaba por criar desigualdades e exclusões, econômicas e sociais.

O olhar histórico demonstra que por longos períodos as políticas indigenistas objetivam integrá-los lógica social e econômica mercadológica, a demarcação e administração de suas terras tinham função produtiva o que levou a um processo de exploração e, muitas vezes, de usurpação de suas riquezas. Parece que, a partir do exemplo de Ventarra, na atualidade as políticas preconizadas pelo Ministério Público, pressupõem, ignorando as mudanças vividas pelos indígenas, em grande medida induzida por política anteriores, que os indígenas devam voltar a viver de forma isolada, independente da sociedade de mercado.

Resta o desafio de aprofundar a análise da política territorial indígena e identificar, com maior profundidade e consistência, formas de permitir que de fato as suas terras estejam a serviço do seu etnodesenvolvimento, evidentemente que para que isso ocorra eles precisam ser os principais sujeitos destas políticas e as necessidades que eles sentem (não as que a sociedade envolvente imaginam) sejam supridas. Não podemos continuar, em nome da preservação da cultura indígena, produzir mais miséria, fome e exclusão dos mesmos. 


\title{
INDIGENOUS TERRITORIAL LAW: BETWEEN TRADITIONAL OCCUPATION AND SUPPORT PRODUCTION
}

\begin{abstract}
This article exposes the evolution of the public politics linked to indigenous land demarcation's in Rio Grande do Sul; the nowadays ways of utilization of these lands, as well as the partnerships between white people and the Indians in the Ventarra's Indigenous Village, which is located in the town of Erebango, the clashes and public blockings through the Ministério Público Federal (Federal Public Ministry) and the Polícia Federal (Federal Police). Through this structure the idea gets to the paradox questioned in this text: a) What needs do Indians have nowadays? b) in which ways can the use of the land supply these needs? c) the possibility of a new vision in public politics which accepts the participation of white people, making the social aims from different cultures equal. The methodology used to the investigation was bibliographical and empirical, where data has been collected directly from the Ventarra's Village.
\end{abstract}

Keywords: Indigenous Village; Self Development; Ethnodevelopment; Multiculturalism; Public politics.

\section{REFERENCIAS BIBLIOGRÁFICAS}

BECKER, Ítala Irene Balise. O índio kaingáng no Rio Grande do Sul. São Leopoldo: UNISINOS, 1995.

CARDOSO DE OLIVEIRA, Roberto. Ação indigenista, etnicidade e o diálogo interétnico. Estudos Avançados, São Paulo. v. 14, n. 40, set./dez., 2000.

Sociologia do Brasil indígena. Rio de Janeiro: Tempo Brasileiro; Brasília: Unb, 1978.

CARINI. Joel. Estado, índios e colonos: O conflito na reserva indígena de Serrinha no norte do Rio Grande do Sul. Passo Fundo: UPF, 2005.

GAGLIARDI, José Mauro. O indígena e a república. São Paulo: HUCITET; USP; Secretaria de Cultura do Estado de São Paulo, 1989.

KUJAWA, Henrique. A política territorial indígena no Rio Grande do Sul durante o século XX. In: TEDESCO, João Carlos ( Org.). Conflitos agrários no norte do Rio Grande do Sul: indígenas e agricultores. Vol. VII. Porto Algre; Passo Fundo: Letra \& Vida; IMED, 2014 (a).

KUJAWA, Henrique. Conflitos territoriais envolvendo indígenas e agricultores no norte do Rio Grande do Sul: a trajetória de políticas públicas contraditórias. Tese de doutorado defendida no PPG/ Ciências sociais da UNISINOS, 2014 (b).

LACERDA, Rosana. Os povos indígenas e a Constituinte 1987-1988. Brasília: CIMI, 2008.

MINISTÉRIO PÚBLICO FEDERAL. Comarca de Passo Fundo. Inquérito Civil Público No 1.29.004.000751/2005-3. 
NAVARRETE, Federico. A invenção da etnicidade nos Estados-Nações americanos no século XIX e XX. In: HEINZ, Flavio; HARRES, Marluza Marques (Org.). História e seus territórios: conferências do XXIV Simpósio Nacional de História da ANPUH. São Leopoldo: Oikos, 2008.

PEZAT, Paulo Ricardo. Augusto Comte e os fetichistas: estudo sobre as relações entre a Igreja Positivista, o Brasil, o Partido Republicano Rio-Grandense e a política indigenista na República Velha. 1997. Dissertação (Mestrado em História) - UFRGS, Porto Alegre, 1997.

RIO GRANDE DO SUL. Relatório e conclusões do Grupo de Trabalho criado pelo decreto n 37118/96 para analisar questões indígenas no Rio Grande do Sul, 1997. (mimeografado)

RIO GRANDE DO SUL, Assembléia Legislativa. Relatório da CPI do Índio, 1968 (mimeo)

RÜCKERT, Aldomar; KUJAWA, Henrique. A questão territorial Votouro/Kandóia no município de Faxinalzinho/RS. Porto Alegre: UFRGS; Passo Fundo: IMED, 2010. (Relatório de Pesquisa).

STAVENHAGEN, R. Etnodesenvolvimento: uma dimensão ignorada no pensamento desenvolvimentista. In: Anuário Antropológico, 1985.

TONET. Fernando. Reconfigurações do constitucionalismo: modelos constitucionais sistêmicos na pósmodernidade. $2^{\circ}$. ed. Rio de Janeiro: Lumen Juris, 2016.

Transformações autopoieticas e a viragem teórica sistêmica estaminal. REDES - Revista Eletrônica Direito e Sociedade. Canoas, vol. 2, n. 1, mai. 2014.

VEIGA, Juracilda. Mudanças no padrão de ocupação e produção nas terras indígenas Kaigang. In: TEDESCO, João Carlos; CARINI, Joel João. Conflitos Agrários no Norte Gaúcho. Vol III, Passo Fundo: IMED, 2010.

VERDUM, Ricardo. Etnodesenvolvimento: nova/velha utopia indigenismo. Tese de Doutorado apresentada no CCPAC, Universidade de Brasília, fevereiro de 2006.

Trabalho enviado em 21 de junho de 2016.

Aceito em 21 de setembro de 2016. 